Dr Popi Sotiriadou

Department of Tourism, Sport and Hotel Management

Griffith University, Gold Coast Campus

Southport Queensland 4222, Australia

Phone: +61-7-555-29241

E-mail: p.sotiriadou@griffith.edu.au

Popi Sotiriadou is a Senior Lecturer in the Department of Tourism, Sport and Hotel Management at Griffith University. Her research interests include sport development, sport policy, high performance sport, and the attraction, retention and nurturing of sport participants. She holds a Graduate Certificate of Higher Education and has grants on "The roles of cooperative education" and on "Enhancing the nexus between teaching and research".

Dr Brad Hill

Department of Tourism, Sport and Hotel Management

Griffith University, Gold Coast Campus

Southport Queensland 4222, Australia

Phone: +61-7-555-28134

E-mail: b.hill@griffith.edu.au

Brad Hill is a Lecturer in the Department of Tourism, Sport and Hotel Management at Griffith University. His research interests include human information processing within leisure and sport advertising and athlete talent selection, leisure and sport facility management and leisure and sport participant motives. 
Using scaffolding to promote sport management graduates’ critical thinking 


\begin{abstract}
Graduates require a capacity to critically think and analyse to successfully assimilate within the workforce. This study uses scaffolding as a framework to improve graduate critical thinking (CT) skills. Graduate students (N=27) in the Master of Business, at an Australian University, majoring in sport management participated in this study. The study involved (a) the use of Beyer' 10-item scale to measure student perceptions of their CT skill improvement, and (b) a rubric based on Bloom's taxonomy to measure teacher evaluations of CT skill development. Scaffolding was used as a method to design progressive assessment items to allow CT skills to develop. Building on sequential assignments, the results show that students’ capacity to explain and analyse issues substantially improves. However, the highest levels of CT are challenging to develop. The paper discusses implications from using scaffolding and recommends strategies for further enhancing CT skills in sport management curricula.
\end{abstract}

Keywords: Critical thinking; graduates; scaffolding; sport management; curriculum development. 
In global knowledge economies, higher education institutions and the globalisation of education offer mediums for a wide range of cross-border relationships and continuous global flows of graduates and knowledge. Such global flows and the reinvention of the world around higher education institutions influence education policies that produce and support graduate learning and skill (Marginson and Wende 2007). Global shifts in tertiary education, such as the Assurance of Learning (AOL) requirements (e.g., Eschenfelder, Bryan and Lee n.d.) and advances in labour market policy, including the effects of the Work Choices and Fair Work reforms (Borland 2011), place universities under increasing pressure to produce employable graduates (Bridgstock 2009). At the same time, evidence suggests that developing skills at higher education institutions may be compromised under the pressure for academics to “publish or perish” (Freudenberg, Brimble, and Cameron 2011, 79).

This balancing act between developing graduate skills and pressures like publishing, is intensified within content-driven courses (or otherwise referred to as subjects), such as sport management courses. This is because general programs (or otherwise referred to as degrees) (e.g., Master of Business Administration-MBA) offer courses preparing students with a general managerial perspective and aptitude, while specialised programs (e.g., Master of Management with a specialisation in sport management) and courses within those programs (e.g., sport and recreation facility management) prepare students for roles in specialist areas of business, management, and other organisation-related professions (Association to Advance Collegiate Schools of Business [AACSB] 2013). As sport management is an established field of study, generic management principles are insufficient and the need to develop and teach sport-specific practices and theories is clear (Sotiriadou 2012). Chalip (2006), in his 2005 Zeigler lecture, addressed this point and demonstrated the distinctiveness of sport management. 
Sotiriadou (2011) stressed the importance of offering content-specific 'programs that provide graduates with the professional competency-based sport management education required by the sport and fitness industry' (541). However, the introduction of rubrics used to gather evidence that measures graduate outcomes for AOL and accreditation purposes with bodies such as the AACSB has added a new dimension into curriculum design; the need to introduce or advance a particular graduate skill within a course (e.g., improving graduate communication skills within a sport marketing course). Including graduate skill development risks shifting the focus from delivering specialised content to a curriculum that builds around promoting these graduate skills instead. In their study of employer needs within the Australian sport management job market Emery, Crabtree and Kerr (2012) found that employers demand that graduates possess a range of skills such as communication, teamwork, critical thinking, and problem solving. In addition, their study shows that employers expect sport management graduates to have sport-specific knowledge and qualifications, reiterating the importance of courses to contain a balance between course specific content and skill development.

Given the multiplicity of pressures for sport management curricula to be all encompassing, there is a need for innovative techniques like, the scaffolding of gradual tasks (Clark and Graves 2005; Oliver and Utermohlen 1995) for achieving both content specific curricula whilst building graduate skills. One such skill important to sport management graduates (Emery et al. 2012) is critical thinking (CT), and has received some attention within disciplines such as nursing (e.g., Boswell 2006) and biology (e.g., Gunersel, Simpson, Aufderheide, and Wang 2008). However, empirical findings on CT skills and curricula design have been largely neglected within sport management courses. Further to this, MacPherson (1999) suggested that well developed CT skills are essential to good management, yet the fundamentals of CT are often not taught explicitly 
to management students. This study examines the use of scaffolding of assessment as a technique to advance CT skills of sport management students without impinging on the delivery and quality of content specific curricula. The study advances the following research question: 'How can scaffolding assist sport management graduates develop critical thinking skills?'. The research question is examined using a cohort of students enrolled in a course of a sport management specialisation in a university graduate business program.

Sport management is an appropriate context to investigate the development of CT skills as this field has enjoyed a decade of exponential growth and has witnessed unprecedented demand for university education (Costa 2005; Shilbury and Kellett 2011). This study contributes to the body of research on the development of graduate CT skills and offers evidence to faculty staff along with ideas on ways to balance content-specific curriculum pressures with AOL requirements and skill development in content-driven programs and courses.

\section{Critical Thinking Skills}

Educational qualification frameworks, such as the Australian qualifications framework (AQF) (Australian Qualifications Framework Council [AQFC] 2013) and the European qualifications framework (European Commission 2008) provide the policy and standards for regulated qualifications in education and training, and require tertiary institutions to build graduate knowledge and skills (AQFC 2013; Brockman, Clarke, and Welch 2009). Skills, according to the AQFC (2013, 11), are what a graduate 'can do' and include:

(a) cognitive and creative skills involving the use of intuitive, logical and critical thinking

(b) technical skills involving dexterity and the use of methods, materials, tools and instruments

(c) communication skills involving written, oral, literacy and numeracy skills 
(d) interpersonal skills and

(e) generic skills.

In sport management, as well as a raft of other disciplines (e.g., Bowles 2000; Roy and Macchiette 2005; Woods, Felder, Rugarcia, and Stice 2000), CT is recognised as a central competency of university graduates (Zakus, Malloy, and Edwards 2007). Critical thinking is the first condition for correct interpretation of information (Araujo 2012). Most formal definitions of CT characterise it as the 'intentional application of rational, higher order thinking skills, such as analysis, synthesis, problem recognition and problem solving, inference, and evaluation' (Angelo 1995, 6).The term has been synonymous with the ability to think clearly and logically and to detect errors and fallacies in the thinking of others (Jones 1997). A fallacy could be best understood as an error of reasoning. When, for instance, someone adopts a position based on a poor piece of reasoning they commit a fallacy. Essentially, CT requires accurate appraisal and understanding of terminology, facts, theories and evidence, and consideration of how information interpreted was analysed in order to develop strong arguments and accurate recommendations (Knowles and McGloin 2007).

As these definitions imply, CT skills resemble the skills required during scientifically based research (Fang, Manuel, Bledsoe, and Bellamy 2008). Therefore, the extent to which students can become proficient at CT is enhanced by creating a climate of inquiry and actively engaging students with assessments that incorporate research (Ornstein and Hunkins 1998). Akin to CT, the research process involves identifying and clarifying the problem or question, determining the information needed and how to obtain it, organising the information obtained, and interpreting the results (Bourner 1996). Critical thinking skills are skills that students need to learn to be able to solve problems. Consequently, CT skills can be encouraged by helping students solve problems (Ornstein and Hunkins 1998). Essentially, CT is evaluative in nature and research based assessment tasks contribute to developing CT 
skills. Burden and Byrd (2013) explain that the components for this problem solving strategy to developing CT skills consist of the following:

(a) students are presented with a problem (or research question).

(b) students gather data and suggest solutions to solve the problem(s).

(c) students describe what is creating the problem or the barriers to its solution.

(d) students analyse the data, compare the results with previous generated knowledge, and construct reports that present the solutions. Burden and Byrd's (2013) four problem solving strategies have been included in a series of research-based assessment tasks for this study.

There have been a number of efforts to identify and group the characteristics of CT. For instance, Wade (1995) explained that CT involves eight characteristics. These are; asking questions, defining a problem, examining evidence, analysing assumptions and biases, avoiding emotional reasoning, avoiding oversimplification, considering other interpretations, and tolerating ambiguity. Beyer's (1988) seminal work on CT provided a comprehensive framework of the 10 CT operations. These include having the ability to (a) distinguish between verifiable facts and value claims, (b) distinguish relevant from irrelevant information, (c) determine the factual accuracy of a statement, (d) determine the credibility of a source, (e) identify ambiguous claims or arguments, (f) identify unstated assumptions, (g) detect bias, (h) identify logical fallacies, (i) recognise logical inconsistencies in a line of reasoning, and (j) determine the strength of an argument or claim. Beyer's (1988) framework is used as a basis for examining student perceptions of the development of their CT skills in this study.

Bloom's Taxonomy

Benjamin Bloom’s information processing skills taxonomy (Bloom, Engelhart, Furst, Hill, and Krathwohl 1956) is the most widely cited source for educational practitioners when 
it comes to teaching and assessing higher-order thinking skills. Kennedy, Fisher, and Ennis (1991) maintain that Bloom's taxonomy is hierarchical, with knowledge at the bottom and evaluation at the top. The three highest levels (analysis, synthesis, and evaluation) are frequently said to represent critical thinking. In this study, the first assessment was used to build student comprehension of the issue at hand (i.e., Bloom's taxonomy level 1, knowledge) through the collection and in-class 20 minute presentation of information on sport venues’ economic sustainability and service qualities. That assignment and assignment two were reflective of Beyer's (1988) framework. The second assessment built on the knowledge that students gained from their data collection to shape working groups in order to demonstrate an understanding of facts and ideas by comparing their findings from assessment 1 (i.e., Bloom's taxonomy level 2, comprehension) and to solve the identified problems by applying acquired knowledge in different ways (i.e., Bloom’s taxonomy level 3, application). Last, a rubric applying the three highest levels (level 4, analysis; level 5, synthesis; and level 6, evaluation) was used for the teacher to measure CT skills from the last assignment for the course, a critical thinking essay. The scaffolding of assessment tasks with the aim to improve CT skills is discussed next.

\section{Scaffolding}

By the mid-1980s, as part of the general education requirements, many colleges and universities offered courses specifically designed to enhance their students' ability to think critically (Halpern 1999). Thomas, Davis and Kazlauskas (2007) argued that 'the fact that universities are being called upon to develop students' critical thinking abilities underlines an assumption that students do not arrive at university with these skills' (328). A key issue within the development of CT is that it takes time to become proficient in this skill (Hatcher 2006). Teachers need to allow adequate time and opportunities in order to maximise benefits from this skill. These opportunities develop as teachers break the whole task (e.g., 
assignment) into smaller, more manageable tasks (Clark and Graves 2005). As students engage in smaller parts of the whole task, completion of the project can take many weeks (Clark and Graves 2005). Sharma and Hannafin (2004) suggested that the gradual learning of CT skills makes the use of scaffolding to adult or mature graduate students an effective approach to use due to graduates’ epistemological readiness to question and seek knowledge. This is in particular important for students with cultural and language backgrounds that are different from that of the classroom (Woodward-Kron and Remedios 2007). The increased length of time scaffolding requires provides opportunities to incorporate development of CT skills into the task. Kuhn (1999) argued that CT evolves developmentally. As such, Thomas et al. (2007) stress that scaffolding tasks, knowledge and skills is an effective way of facilitating the evolving nature and development of CT skills in students. In spite of that, the extent to which this application can translate to a sport management context and in particular to graduate students remains to be explored.

Scaffolding originates from Lev Vygotsky’s (1963) socio-cultural theory. Taking socio-cultural ideas as a starting point enabled the synthesis of theoretical ideas about the development of mental actions and teaching strategies for efficient formation of new knowledge (Arievitch and Haenen 2005). Modern research continues to find that scaffolding is an effective and student-centred teaching strategy (Athanassiou, McNett and Harvey 2003). Scaffolding, as an educational technique, has become a useful tool in engaging students at deeper levels of learning allowing them to complete tasks in a more proficient manner and improve skills (Clark and Graves 2005). Holton and Clarke (2006, 131) define scaffolding as a teaching technique that (a) 'supports the immediate construction of knowledge by the learner”, and (b) “provides the basis of independent learning of the individual'.

Scaffolding provides students with sections of the task that may be beyond their limits initially (Walton and Archer 2004). This allows the student to focus on the parts of the task 
that they can manage. As the student's abilities increase the scaffolding provided initially is progressively withdrawn. Eventually, the student has the ability to complete the task independently (Chang, Chen and Sung 2002). One of the primary benefits of scaffolding is that it engages the learner. The learner 'does not passively listen to information presented instead, through teacher prompting the learner builds on prior knowledge and forms new knowledge’ (Van Der Stuyf, 2002, 11-12). In addition, scaffolding allows the teacher to keep a task whole, while students can learn, understand, and manage smaller parts of the task. The goal of the teacher when using scaffolding is for the student to become an independent and self-regulating learner and problem solver or critical thinker (Hartman 2002). Given the intertwined nature between CT skills and the ability to solve problems, it can be argued that scaffolding may provide a useful framework to enable the development of such skills. This study explores that assumption.

Scaffolding can be provided by giving students a 'lens' or 'framework' through which to study a problem (Kaste 2004; Walton and Archer 2004). Young and Bender-Slack (2011) for instance asked students to evaluate a number of websites. The students were then given a framework to evaluate the websites based on the variables/metrics in that framework. In Kaste's (2004) study, students used the lens of a diverse constructivist orientation to study cases and recognise the place of the students' language, social class, and ethnicity in literacy learning. Kaste (2004) discovered that she utilised a lot of scaffolding at the beginning but gradually her input reduced over time. Dawn, Dominguez, Troutman, Bond, and Cone (2011), in their research used the hypothesis that an instructional approach using targeted scaffolding would improve student abilities to critically evaluate clinical literature compared to more lecture-based didactic instruction. They found that using scaffolding improved students' ability to critically evaluate a clinical study better than lecture-based coursework alone. This study adopts the framework-based method of scaffolding and allows students to 
use a framework (e.g., the World Stadium Index [Alm, 2012]) as a lens to understand and study the economic sustainability of sport event venues and facilities, and the service quality or customer expectations.

\section{Method}

Sample and statistical power

The population and sample for this study were graduate students $(\mathrm{N}=27)$ specialising in sport management in the Masters of Business degree at a University in Australia. Eligible students had to meet certain admission and language requirements in this degree. Specifically, to be eligible for admission to the Master of Business program, a student must hold a Bachelor's degree in a related discipline from a recognised University with a minimum grade point average of 4.0 (using a 7.0 point scale), or hold a non-related Bachelor's degree from a recognised University with a minimum grade point average of 4.0 (using a 7.0 scale) plus a minimum of two years equivalent full-time professional work experience in a related field. Within the university where the study was conducted English language requirements apply to International applicants and other applicants whose previous study was undertaken in a language other than English (e.g., a minimum score of 575 on TOEFL). The majority of the sample of students (19 out of 27) were from Asia (7 students) and Europe (12 students) with English as their second language. Also, 18 of these students were male and 9 female. A post hoc statistical power analysis with program $G^{*}$ Power (Erdfelder, Faul, and Buchner 1996) was conducted to determine whether the sample size and design of the study demonstrated adequate power to detect effects of scaffolding technique on CT skills. Power analysis revealed a medium-strong sized effect ( $f=0.7$; $c f$. Cohen 1988) could be detected at .95 critical $t(28)=2.05, \mathrm{p}=.05$ when the type of statistical test used in this study (i.e., onesample $t$ test), was taken into account with sample size. Cohen (1988) indicated a power 
value of .80 should be achieved to ensure that the probability of a statistical significance test had gathered enough evidence to correctly reject the null hypothesis in preference for the alternate hypothesis. As a power value of .95 was obtained the sample size for this study was deemed adequate for statistical analysis.

Student and teacher based data collection processes

Once permission to conduct the study was granted by the department's teaching and learning ethics committee, two groups of data were collected during the last week (week 13) of the teaching semester (semester 2), week 13 in 2012. Applying Beyer's (1988) 10-item scale, the first group of data were collected using a short in-class survey with 5-point Likert type questions ( $1=$ 'strongly agree' to $5=$ 'strongly disagree'). The purpose of the survey was to measure how students perceived improvement of their CT skills (self-evaluation). Students were asked to rank the extent to which scaffolding helped them attain each of Beyer's (1988) 10 CT skills.

Using the last piece of assessment for the course (a critical thinking essay), the second group of data facilitated the teacher's assessment of student development of CT skills. This assessment was based on the criteria used in a rubric designed to measure development of higher order CT skills (i.e., Bloom's taxonomy levels 4, 5 and 6).

\section{Data analyses}

Factor analysis was conducted on Beyer's (1988) 10-item CT scale to check unidimensionality. Factor analysis revealed that scale items loaded onto one factor and explained $63 \%$ variance. When conducting factor analysis on small sample sizes communality of items and variables play a more important role than sample size itself (MacCallum, Widaman, Zhang and Hong 1997). MacCallum et al. (1997) suggested when communalities are 
consistently high (i.e., greater than .6), sample size can be afforded a low weight and good recovery of population factors can be achieved with sample sizes traditionally believed too small for factor analytical studies. Inspection of communalities on all ten items within the CT scale revealed scores greater than .6. Hence, the sample size was adequate. These findings indicate that the scale items were appropriate for measuring CT skills. Good reliability was demonstrated by achieving a Cronbach's alpha score of $\alpha=.93$.

One-sample $t$-tests were used to determine significant differences between zero and sample means on each item. A one-sample t-test measured students' perception of overall effects of scaffolding on CT skills. A series of paired samples t-tests were conducted between all significant items to determine if certain CT skills were found to improve more than others.

The CT skills rubric was designed using five levels (from 'excellent' to 'unsatisfactory') to assess each of the four criteria used. The first criterion (explanation of issues in relation to building/renovating sport venues) was used to allow students to introduce the problem to the reader. The second criterion (presentation of analysis) was used to measure Bloom's level 4 CT skill development; analysis. This criterion was also used to measure how well, clearly and succinctly students can present their analyses. The third criterion (interpretation of findings) was used to measure level 5 CT skill development; synthesis, and the fourth criterion (outcomes and implications) was in place to assess the highest level 6 CT skill development; evaluation.

\section{Scaffolding of assessments}

During week 2 of the semester, students were briefed on the details of their assignment. Using a sport and recreation venue of their choice, students working in pairs had to conduct a study to identify whether this facility (a) is leaving a positive economic legacy (after it was built/renovated), and (b) spectators/visitors are satisfied with the service/quality 
of this venue. Then, during week 7 of the semester they had to present their findings in order to complete the first assignment which was a PowerPoint presentation of their findings. The presentation was worth $30 \%$ of their total mark for the course. In order to complete the first part of their presentation (the economic legacy of the venue) students collected relevant information for their venue using the World Stadium Index (WSI) (Alm 2012). In order to collect information for the second part of their presentation (the service/quality of the venue) students were given a list of articles that have developed or used customer or spectator expectation scales (e.g., Wright, Duray, and Goodale 1992), satisfaction or Servicescape measures (e.g., Hill and Green 2012) to choose from.

Assessment 2, an evidenced based report, (worth $40 \%$ of the total mark) 'builds on' the findings and knowledge that students gained from Assessment 1 (i.e., Assessment 1 was the scaffold for Assessment 2). For Assessment 2 (the evidenced based report), small groups of three students who each examined a different venue during the first assessment came together in order to conduct comparisons of their findings and submit a 4,000 word report. Students were advised to consider the feedback they received from their first assignment to improve the quality of the second assignment as feedback forms an important part of a properly constructed scaffolding strategy (Thomas et al. 2007). Assessment 2 was an opportunity for students to start developing and showcasing their CT skills and their capacity as a group to interpret the findings offered for all of the venues examined in Assessment 1 in a meaningful and constructive way. An essential aspect of Assessment 2 was the comparison of the venues and student reflections on which venues(s) performed well and why, as well as which venues underperformed and why. In addition, Assessment 2 required students to offer recommendations or suggestions on how to best improve the poorly performing venues (i.e., suggest solutions to existing problems) and sustain the good performing venues (i.e., suggest benchmarks to venue managers). 
Assessment 3 was an individual essay (worth 30\%) designed to examine the culmination of student knowledge and CT capacities. These skills were assessed using a rubric designed in accordance with Bloom's taxonomy higher order levels of CT skills. Assignment 3 was a critical thinking in-class essay during week 13. Students were given the topic Build it and they will come and essay instructions, and were asked to critically analyse the topic. The topic suggests that building sports and leisure facilities drives public interest and visits to venues. In order to assess the student ability to complete the task independently (Chang, Chen, and Sung 2002), and evaluate deeper levels of skill development (HeijnePenninga, Kuks, Schönrock-Adema, Snijders, and Cohen-Schotanus 2008) students were not permitted to use $\mathrm{Wi}-\mathrm{Fi}$, or notes and other materials.

In order to comply with University requirements for moderating the marking of the assessments, another faculty member was assigned with the task of marking a series of assessments representing excellent, good, average and low performing student results. Assignment moderation revealed consistency of marking between assessors. In addition to the rubric that was introduced and explained in advance to students, instructions were given in terms of what was expected of them in order to perform well. For instance, students knew they had to express their opinion, prioritise ideas, justify and explain their position, present different aspects of the argument and alternative solutions, and elaborate on ways they would change things to manage various situations.

During the semester, in order to enrich the curriculum and help build content-related knowledge students received relevant materials (e.g., articles, book chapters on sport facilities), engaged in workshops, visited two venues, conducted case studies, and engaged in group discussions. Materials provided to students included the instruction sheets for the stages of the activities and tips, the CT rubric, and a reference list on various frameworks 
utilised to measure customer or spectator expectation and features of the facilities (i.e., Servicescape).

\section{Results}

Survey Results

Factor analysis was conducted on the 10 items in the CT scale to check unidimensionality. Factor analysis revealed that scale items loaded onto one factor and explained 63\% variance. This finding indicates that the scale items were appropriate for measuring CT skills. Good reliability was demonstrated by achieving a Cronbach’s alpha score of $\alpha=.93$.

One-sample $t$-tests were used to determine significant differences between zero and sample means. A first test assessed overall results. All 10 items in the CT skills measured were totalled and averaged and then tested against zero. This test determined whether, overall, students' perceived development of CT skills occurred through use of scaffolding technique. A second test assessed each of the ten individual items of the scale to determine which items might be more effective than others in developing CT skills through scaffolding.

Data gathered through the CT scale were recalibrated and centred against zero. Results from centred data show whether respondents, on average, either did or did not perceive improvement from scaffolding on CT skills. The midpoint of each scale represents a point of indifference. In other words, scores above the midpoint (i.e., zero) represent agreement with the statement being measured, while scores below the midpoint represent disagreement. Setting the scale midpoint at zero, a score of zero represents indifference. Scores significantly higher than zero indicated that respondents found scaffolding to be salient for improving CT skills. Scores significantly below zero indicated that respondents found scaffolding to not be useful in developing CT skills. Scores at the point of indifference (i.e., scores found not to be 
significant in either direction) indicated that scaffolding was not salient to respondents (cf. Hinkle, Wiersma, and Jurs 1994) for improving CT skills.

A one-sample t-test measuring students' perception of overall effects of scaffolding on CT skills was found to be significant. $t(24)=3.27, p<.05$. Inspection of the mean score reveals a positive result $(M=.552)$. Together, these findings indicate that students perceived significantly favourable outcomes in developing CT skills from the use of scaffolding.

To gain a deeper understanding for which items within the CT skills scale students' perceived provided significant improvement through using scaffolding technique, a series of one-sample $t$-tests were conducted on all ten items. As a number of one sample $t$-tests were conducted on the same sample, it was necessary to protect the confidence level against type one errors. Bonferroni's criterion was used. In practice, the number of variables being subjected to univariate testing (in this case, 10) divides the alpha level (.05). For this study, the type one error rate is protected at .05 by requiring the observed probability for any $t$-test to be equal to or less that $.05 \div 10$, which is .005 (Whitney and Feldt 1973).

Table 1

Descriptive and Inferential Statistics of Students' Perceived Improvement on Individual CT Skills through use of Scaffolding

Item

$M \quad S D \quad d f \quad t$

Distinguish facts from assertions

$.63 \quad 1.04 \quad 26 \quad 3.13^{*}$

Distinguish relevant/irrelevant information

$.59 \quad 1.01 \quad 26 \quad 3.05^{*}$

Determine statement accuracy

$.52 \quad .85 \quad 26 \quad 3.17 *$ 
Identify unstated assumptions

Recognise logical inconsistencies

Determine strengths of arguments or claims

Determine source credibility

Detect bias

Identify logical fallacies or errors

Identify ambiguous claims or arguments $\begin{array}{llll}.67 & .83 & 26 & 4.16 *\end{array}$

$.59 \quad .97 \quad 26 \quad 3.17^{*}$

$.85 \quad 1.13 \quad 26 \quad 3.90 *$

$\begin{array}{llll}.42 & 1.13 & 25 & 1.90\end{array}$

$\begin{array}{llll}.56 & 1.18 & 26 & 2.43\end{array}$

$\begin{array}{llll}.46 & 1.14 & 25 & 2.07\end{array}$

$\begin{array}{llll}.30 & .95 & 26 & 1.62\end{array}$

$* \mathrm{p}<.005$, two-tailed.

Table 1 shows that the following items were perceived by students to have significantly improved through the use of scaffolding: distinguish facts from assertions, distinguish relevant/irrelevant information, determine statement accuracy, identify unstated assumptions, recognise logical inconsistencies, and determine strengths of arguments or claims. Students did not perceive any improvement on CT skills for the following items; determine source credibility, identify ambiguous claims or arguments, detect bias, and identify logical fallacies or errors.

A series of paired samples $t$-tests were conducted between all significant items to determine if certain CT skills were found to improve more than others. Bonferroni criterion was used to protect the confidence level against type one errors. As six CT skills were found significant this number divides the alpha level (.05). The error rate is protected at .05 by requiring the observed probability for any $t$-test to be equal to or less that $.05 \div 6$, which is .0083 (Whitney and Feldt 1973). No significant differences were found between any of the six CT skills. The results suggest all six significant CT skills were found to improve similarly 
through scaffolding. Factor analysis on those six items revealed they explained $69.7 \%$ of the variance.

\section{Rubric results}

The first criterion (Criterion 1: Explanation of issues in relation to building or renovating sport venues) required students to introduce the problem to the reader. Hence, it acted as the introduction to the essay. The results show the performance of most students (almost 67 per cent, see Figure 1) was excellent or very good as they were able to clearly identify and explain the issues in relation to building or renovating sport venues. These issues revolved around spending large amounts of money toward building or renovating sport venues, lack of community consultation in the planning process, low post-event usage of venues, and limited ability to convert venues for versatile and multipurpose usage.

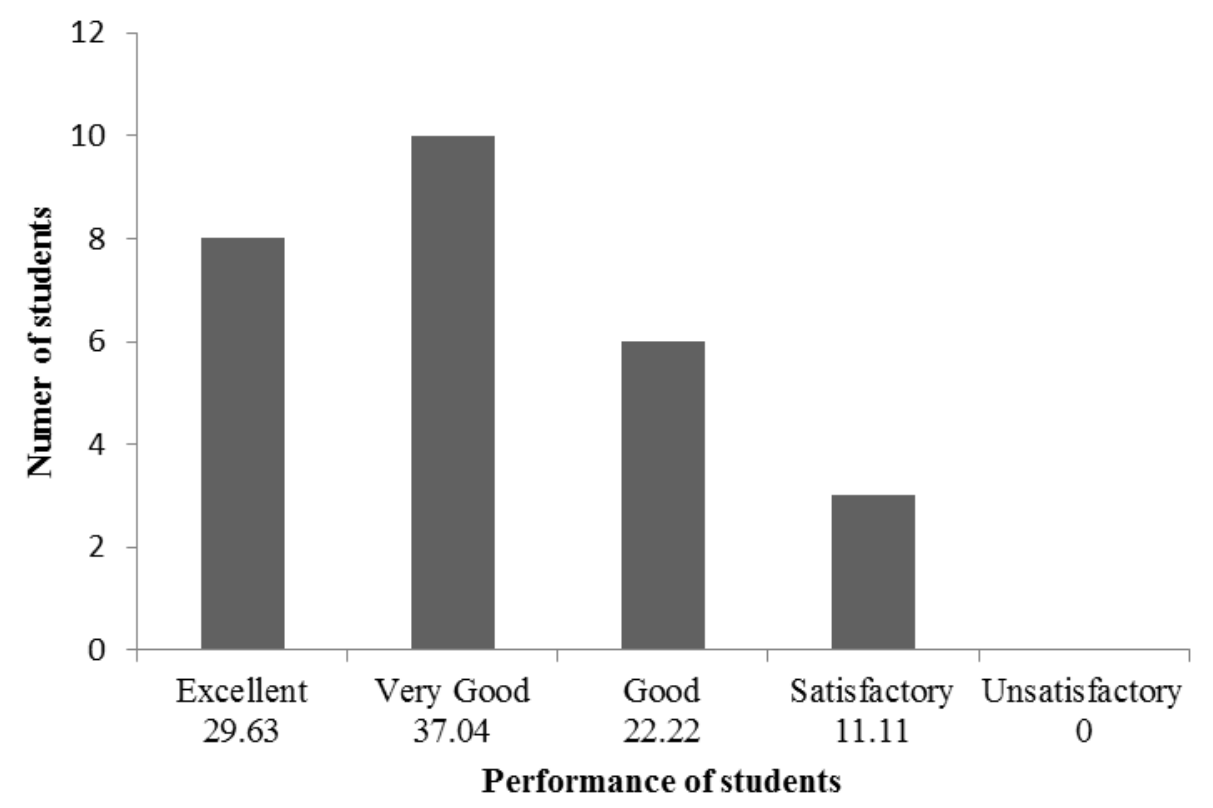

Figure 1. Criterion 1 - Explanation of issues in relation to building/renovating sport venues 
The second criterion (Criterion 2: Presentation of analysis - selecting and using information to investigate the issue) was used to measure Bloom's level 4 CT skill development; analysis. This criterion required students to examine and break information into parts by identifying motives or causes, and find evidence to support generalisations. This criterion was also used to measure students' ability to present their analysis in a wellstructured, clear, and syntax-error free manner. Most students (about 67 per cent, see Figure 2) were able to categorise and identify the different parts of an issue, discuss ideas and find evidence that would justify a situation, and make distinctions and draw relationships between issues.

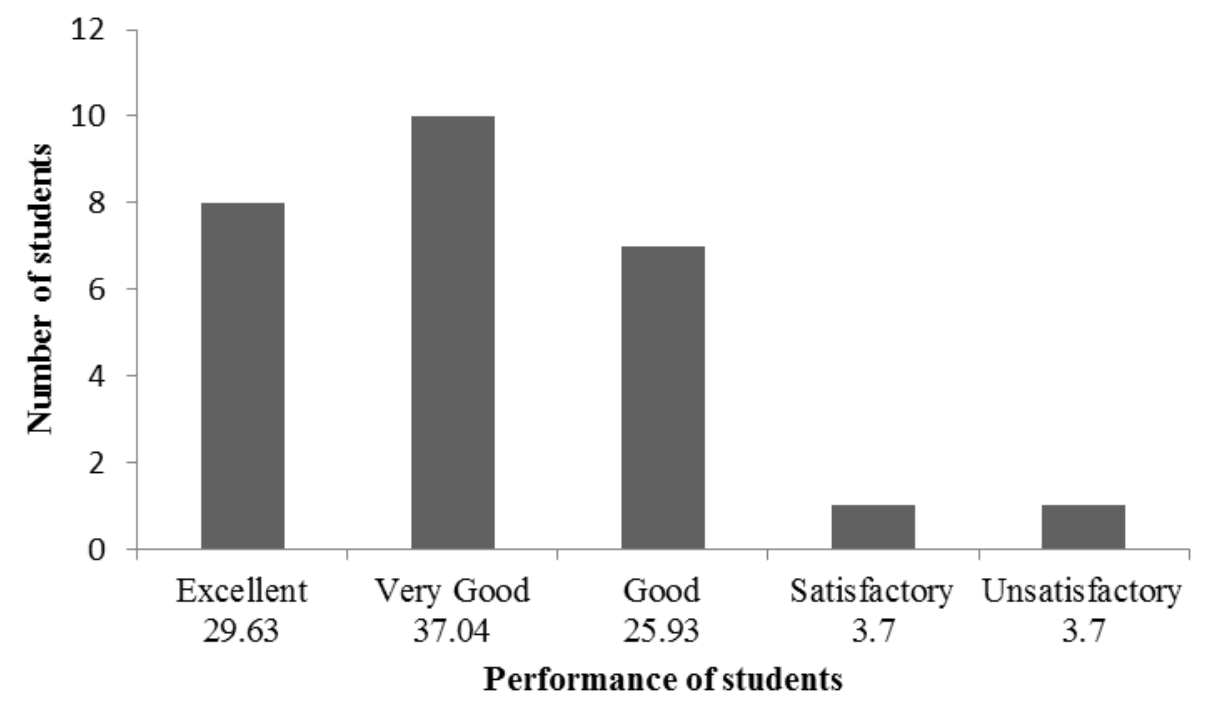

Figure 2. Criterion 2 - Presentation of analysis

The third criterion (Criterion 3: Interpretation of findings) was used to measure Bloom's level 5 CT development; synthesis. Criterion 3 required students to bring information together by combining elements in a new pattern or proposing alternative solutions. Many students (almost 60 per cent, see Figure 3) were able to integrate different positions and 
provide perspectives from different stakeholder views to an excellent (85 per cent or more) or very good (between 65 and 84 per cent) standard.

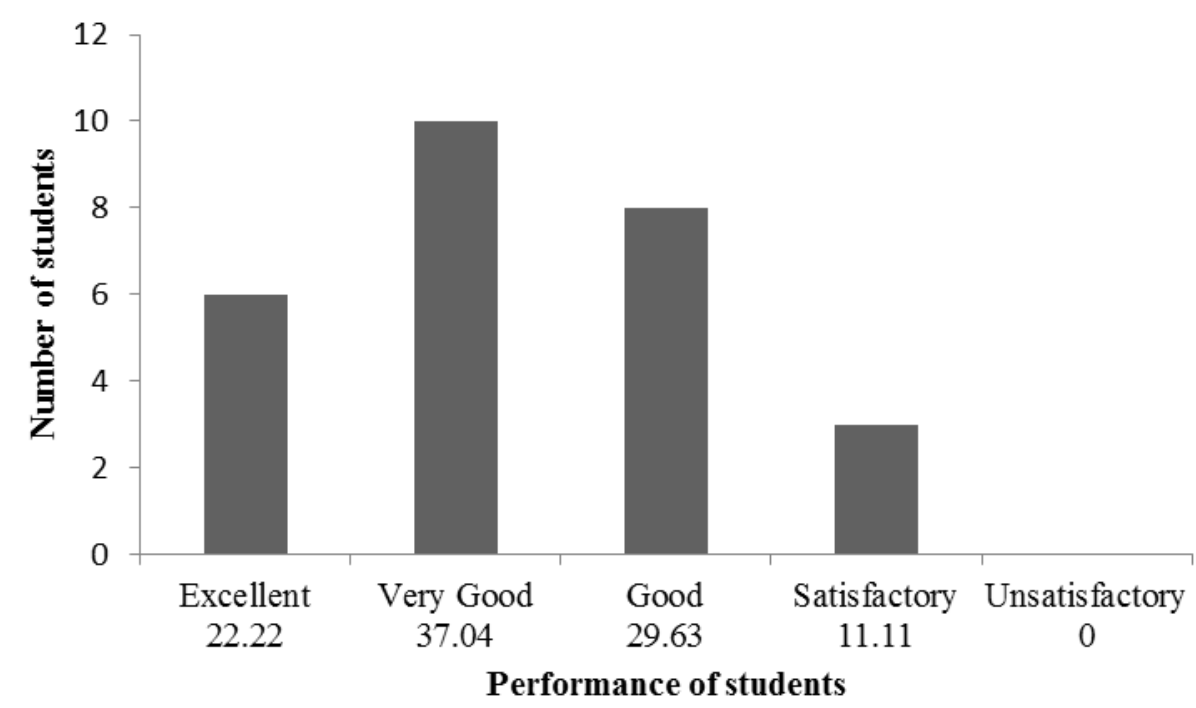

Figure 3. Criterion 3 - Interpretation of findings

For instance, students interpreted the various issues from the perspective of the local or state government, private sector or sponsors, local or broader community, sporting federations or sporting organisations, users, spectators or fans. The results showed that students were able to put forward ideas on changes they would make to solve issues and improve a situation. They were also able to elaborate on their reasoning and considered 'what if' scenarios. A slight drop in overall performance of students in this criterion was observed.

The last criterion (Criterion 4: Conclusion and evaluation of related outcomes) was used to assess Bloom's level 6 CT skill development in students; evaluation. Hence, it also acted as the conclusion to the essay. Students were required to present and defend their opinions by making judgements about information, or the validity of ideas. 


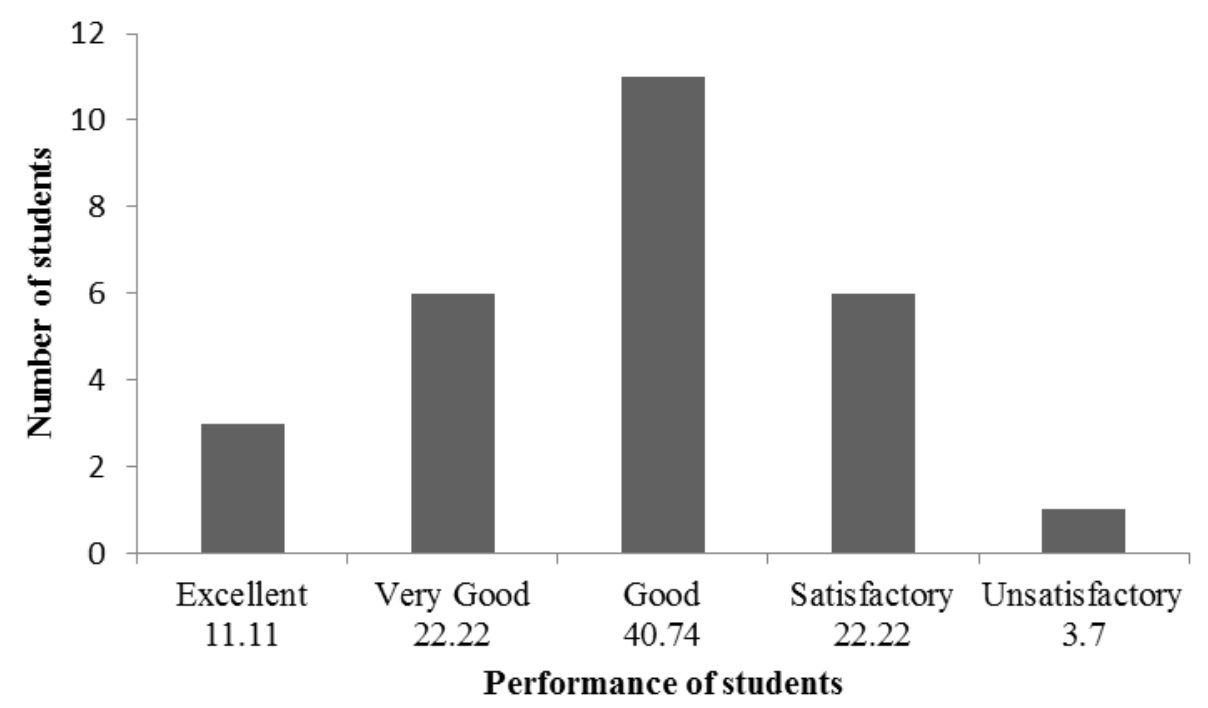

Figure 4. Criterion 4- Conclusions and evaluation of related outcomes

As Figure 4 shows only nine students achieved excellent or very good results in articulating their opinions, making informed recommendations, clearly identifying and presenting logical consequences and implications.

\section{Discussion}

The objective of this study was to implement and assess the role of scaffolding in assisting sport management graduates develop CT skills. The findings from teacher evaluations using the rubric indicate favourable outcomes on students' development of CT skills. The overall pattern shows excellent and very good performances across most of the criteria with potential to improve student capacity to identify and discuss implications and consequences of issues. Also, it appears that progressive assessment tasks offer the scaffold and time needed for students to build CT skills. Specifically, the findings on Criterion 1 indicate that student exposure to weekly workshops, readings, industry workshops, site visits, and group discussions were successful techniques to shape initial knowledge as well as develop the ability to recognise and recall knowledge of specific facts. This ability is 
reflective of Bloom et al.’s (1956) lower level CT skill of knowledge. Hence, it could be argued that curriculum specific content and activities help students develop lower level CT skills and retrieve relevant knowledge from long-term memory and explain issues in relation to building/renovating sport and recreation venues.

The results on Criterion 2 provide a very positive picture of student performance on their ability to critically analyse the issues in a structured manner, with the use of correct grammar and syntax. This is an important outcome given that for the majority of students (19 out of 27) English was their second language and the essay was written in class without external or computer assistance, preventing students from artificially enhancing the quality of their work. This finding supports the notion that scaffolding of assessment was the pedestal which assisted students move beyond merely recalling facts to the more complex CT skill of understanding, comparing, and explaining various issues (Bonk and Smith 1998; Halpern 1999). Kennedy et al. (1991) too concluded that instructional interventions aimed at improving students' CT skills show positive results. This finding indicates that students improved their CT skill of analysis (Bloom et al. 1956) using scaffolds.

The results on Criterion 3 show positive outcomes on students' ability to interpret detail and to provide different perspectives from various standpoints. It is likely that students performed well in this criterion because in addition to scaffolding, students were provided with a lecture and video on critical thinking, and techniques on ways to identify, integrate different positions, and provide different perspectives. Alongside this lecture there was a workshop with case studies on the role of various sport facility stakeholders (e.g. local community, governments, and sponsors) and their different interests and needs. Blending (a) sport management and facility related curriculum materials and (b) scaffolding of assessment has had a positive impact on student learning and their capacity to interpret deferent positions from different stakeholder perspectives. This indicates that scaffolding of assessment can be 
supported by curriculum specific content for optimal learning outcomes (e.g., Knight 2001) and can assist in building Bloom et al.’s (1956) level 5 CT skill of synthesis.

The results on Criterion 4 show overall good performance in student capacity to identify and discuss implications and consequences of sport facility related issues. However, there appears to be a drop in performance compared to the other three Criteria. Criterion 4 was used to measure Bloom et al.'s (1956) highest level of CT skill, evaluation. It could be argued that as this skill is at the top of the typology it may be the hardest to develop. It is suggested that this criterion should be introduced earlier in an assignment as a scaffold to allow students time to develop their evaluation skills and perform better in the last assignment. For instance, in Assessment 2 (the evidenced based report) students can be asked to identify and examine the component parts of the topic, and to examine these component parts in terms of their inter-relationships and their relationship with the whole.

The findings from student perceptions of the development of their CT skills using scaffolding show an improvement in (a) distinguishing facts from assertions, (b) distinguishing relevant/irrelevant information, (c) determining statement accuracy, (d) identifying unstated assumptions, (e) recognising logical inconsistencies, and (f) determining strengths of arguments or claims. These findings suggest that progressive assessment helps develop CT skills. It also reiterates previous findings which suggest that research based assessment tasks contribute to developing CT skills (e.g., Ornstein and Hunkins 1998).

No effects were found on determining source credibility and on identifying ambiguous claims or arguments. This finding suggests that scaffolding is perhaps not useful in helping students determine source credibility and identifying ambiguous claims. In particular, graduate students are expected to be equipped with the ability to recognise credible sources (e.g., official government websites, peer-reviewed journal articles, and reputable 
news sources) from sources that are often considered less credible (e.g., blogs, and individual or business websites). Similarly, ambiguous claims are statements that are subject to multiple interpretations (Empson 2004). Most commonly, this is caused due to a word that has more than one meaning (semantic ambiguity) or due to poor grammar and sentence structure (syntactic ambiguity) (Hagoort 2003). Similarly, it can be postulated that as postgraduate students have developed academic writing skills during their previous education scaffolding does not affect their capacity to identify ambiguities. In addition, the teacher evaluation results show that overall students' capacity to write in a syntax and grammar error-free fashion was well developed.

Also, no effects were found on detecting bias and on identifying logical fallacies or errors. This finding is perplexing and presents a challenge in drawing an interpretation. Interestingly, the literature suggests that the ability to identify fallacies/errors, ambiguous claims, and biases are related terms (Zeigler, Lederman, and Taylor 1992) and associated with higher order levels of CT skills, such as evaluation (Bloom et al., 1956). This finding appears to be consistent with the teacher evaluation findings on the relative difficulty in developing Bloom’s higher level of CT skill, analysis that were presented earlier.

Besides validating the use of scaffolding to promote CT skills in the context of sport management courses, this study's findings help draw several practical recommendations for faculty teachers and curriculum consultants. A key implication from this study is the importance of blending the curriculum content with the scaffolded assessment tasks in order to optimise the skill learning benefits. That blend between advancing sport management related content and skill development assessment tasks can take place without compromising the curriculum in favour of developing skills. Another implication of this study is the importance of introducing aspects of high order CT skills, like evaluation, earlier in the process of scaffolding the assessment. This will allow greater time for students to build those 
skills. Scaffolding provided the kinds of thinking experiences that enabled students to develop CT. In the process, it is suggested that students are carefully guided to recognise fallacies in arguments, detect bias and recognise ambiguous claims. As grades alone are inefficient and indirect evidence of student learning (Suskie 2004), the use of direct measures in addition to student grades is recommended for the AOL process and to meet accreditation expectations such as those required by AACSB. These recommendations should help sport management programs and faculty staff to implement AOL processes and improve student learning.

\section{Conclusion}

This study examined the use of scaffolding as a technique to improve students' CT skills. It was found that scaffolding the assessment tasks is a useful approach to significantly improve students' overall CT skills. For faculty staff that have never used this approach to teaching, this paper provides a simplified approach to how they may engage in doing something similar. The findings in this study address Emery et al.'s (2012) call for strengthening sport management graduates skills and responds to the apparent deficit in the labour market. Also, the study helps draw several conclusions. A scaffolding approach which integrates research, or problem-based assessment in order to expose students to industry practices promotes the development of CT skills. This model of learning promotes student opportunities to develop their CT skills. Identifying problems and solutions to these problems and shifting to higher order thinking along with critically analysing situations can be a challenging task for many students. Therefore, students need a fertile environment to allow them to cultivate these skills. The use of scaffolding as a curriculum development tool creates a learning culture in which students could say 'This is a hard assignment, but I can achieve it' and they believed in their ability to take on the challenge and succeed. This model of delivery: 
a) allows students to develop CT skills and enhance graduate outcomes for AOL purposes,

b) offers a much needed shift from traditional delivery models in order to balance curriculum requirements for content specifics courses with AOL pressures for development of skills, and

c) uses research and problem-based strategies to increase the quality of teaching and of student learning, and improves student learning outcomes and experience.

The findings on teacher assessment and student perceptions on the development of CT skills using scaffolding indicate favourable outcomes. Such findings may be used by curriculum consultants and academics to design a curriculum that promotes the development of CT skills in social sciences and in particular sport management. This study contributes to the body of research on the development of graduate CT skills and offers evidence to faculty staff along with ideas on ways to balance curriculum pressures with AOL requirements and skill development in social science content-driven programs and courses. Teacher-oriented approaches to learning, in which students are passive receptors of knowledge, are largely outdated. Without eliminating standard lectures and guided practices, teaching approaches ought to be based on the philosophy that the teacher is like a coach to students (Lewis 2000). Adapting a scaffolding approach allows students to have an active role in their learning. The role of the teacher is then to guide students in their pursuit of knowledge, acting as a facilitator. This approach makes 'gained knowledge more valuable, well learned, and better retained' (Leo Harrison, in Burden and Byrd 2013, 154). The use of scaffolding is an innovative curriculum development with strong potential to improve sport management student learning outcomes and student experience. 


\section{References}

Alm, J. 2012. World Stadium Index: Stadiums Built for Major Sporting Events - Bright Future or Future Burden? Play the Game/Danish Institute for Sports Studies. $\begin{array}{lllll}\text { Copenhagen, } & \text { København. } & \text { Retrieved } & 6 & \text { August }\end{array}$ http://www.playthegame.org/fileadmin/documents/World_Stadium_Index_Final.pdf

Angelo, T.A. 1995. "Beginning the Dialogue: Thoughts on Promoting Critical Thinking: Classroom Assessment for Critical Thinking.” Teaching of Psychology 22 (1): 6-7.

AQFC. 2013. Australian Qualifications Framework Second Edition, January 2013: South Australia.

Araujo, M. 2012. Applying Critical Analysis Methods-Main Methods. Medwave (12): 2, E5310.doi: 10.5867/medwave.2012.02.5310

Arievitch, I. M., and J. P. Haenen, 2005. Connecting Sociocultural Theory and Educational Practice: Galperin's Approach. Educational Psychologist 40 (3): 155-165.

Athanassiou, N., J.M. McNett and C. Harvey (2003) Critical Thinking in the Management Classroom: Bloom's Taxonomy as a Learning Tool. Journal of Management Education, 27:5, 533-555

Beyer, B.K. 1988. Developing a Thinking Skills Program, Boston, MA: Allyn \& Bacon.

Bloom, B.S. (Ed.), M.D. Engelhart, E.J. Furst, W.H. Hill, and D.R. Krathwohl. 1956. Taxonomy of Educational Objectives: The Classification of Educational Goals. Handbook 1: Cognitive domain. New York: David McKay.

Bonk, C.J., and G.S. Smith. 1998. Alternative Instructional Strategies for Creative and Critical Thinking in the Accounting Curriculum. Journal of Accounting Education16 (2): 261-293. 
Borland, J. 2011. The Australian Labour Market in the 2000s: The Quiet Decade. Retrieved 27 June 2013from http://www.rba.gov.au/publications/confs/2011/pdf/borland.pdf

Boswell, C. 2006. The Art of Questioning: Improving Critical Thinking. Annual Review of Nursing Education 4: 291-304.

Bourner, T. 1996. The Research Process: Four Steps to Success. Research methods: Guidance for postgraduates:7-11.

Bowles, K. 2000. The Relationship of Critical-Thinking Sills and the Clinical-Judgment Skills of Baccalaureate Nursing Students. Journal of Nursing Education 39 (8): 37376.

Bridgstock, R. 2009. The Graduate Attributes we’ve Overlooked: Enhancing Graduate Employability Through Career Management Skills. Higher Education Research \& Development 28 (1): 31-44.

Brockman, M., L. Clarke. and C. Winch. 2009. Difficulties in Recognising Vocational Skills and Qualifications Across Europe. Assessment in Education: Principles, Policy and Practice 16 (1): 97-109.

Burden, P.R., and D.M. Byrd. 2013. Methods for Effective Teaching: Meeting the Needs of all Students. (6th edn.). NY: Pearson.

Chalip, L. 2006. Toward a Distinctive Sport Management Discipline. Journal of Sport Management 20 (1): 1-21.

Chang, K., I. Chen, and Y. Sung. 2002. The Effect of Concept Mapping to Enhance Text Comprehension and Summarization. The Journal of Experimental Education 71 (1): $5-23$. 
Clark, K.F., and M.F. Graves. 2005. Scaffolding Students Comprehension of Text. The Reading Teacher 58:570-580.

Cohen, J. 1988. Statistical Power Analysis for the Behavioral Sciences (2nd ed.) Hillsdale, NJ: Lawrence Erlbaum Associates.

Costa, C.A. 2005. The Status and Future of Sport Management: A Delphi Study. Journal of Sport Management 19: 117-142.

Dawn, S., K. Dominguez, W. Troutman, R. Bond, and C. Cone. 2011. Instructional Scaffolding to Improve Students' Skills in Evaluating Clinical Literature. American Journal of Pharmacuetical Education 75 (4): 62-76.

Emery, P.R., R.M. Crabtree, and A.K. Kerr. 2012. The Australian Sport Management Job Market: An Advertisement Audit of Employer Need. Annals of Leisure Research, 15, 335-353.

Empson, W. 2004. Seven Types of Ambiguity (Vol. 645). Random House.

Erdfelder, E., F. Faul, and A. Buchner. 1996. GPOWER: A General Power Analysis Program. Behavior Research Methods, Instruments, \& Computers 28: 1-11.

Eschenfelder, M. J., L.D. Bryan, and T.M. Lee. 2013. Motivations, Costs and Results of AOL: Perceptions of Accounting and Economics Faculty. Journal of Case Studies in Accreditation and Assessment 3: 1-14. Retrieved 6 August 2013from http://www.www.aabri.com/manuscripts/121347.pdf

European Commission. 2008. Explaining the European Qualifications Framework for Lifelong Learning. Luxembourg: Office for Official Publications of the European Communities. Retreived 28 Junefrom http://ec.europa.eu/dgs/education_culture 
Fang, L., J. Manuel, S.E. Bledsoe, and J. Bellamy. 2008. Finding Existing Knowledge. In Grinnell, R.M. \& Unrau, Y.A. (Eds.), Social Work Research and Evaluation: Foundations of Evidence-based Practice (p. 466). Oxford: Oxford University Press

Freudenberg, B., M. Brimble, and C. Cameron. 2011. WIL and Generic Skill Development: The Development of Business Students' Generic Skills Through Work Integrated Learning. Asia Pacific Journal of Cooperative Education 12 (2): 79-93.

Gunersel, A.B., N.J. Simpson, K.J. Aufderheide, and L. Wang. 2008. Effectiveness of Collaborated Peer Review (TM) Improving Writing and Critical Thinking Skills in Biology Undergraduate Students. Journal of the Scholarship of Teaching and Learning 8 (2): 25-37.

Hagoort, P. 2003. Interplay Between Syntax and Semantics During Sentence Comprehension: ERP Effects of Combining Syntactic and Semantic Violations. Journal of Cognitive Neuroscience 15 (6): 883-899.

Halpern, D. 1999. Teaching for Critical Tthinking: Helping College Students Develop the Skills and Dispositions of a Critical Thinker. New Directions for Teaching and Learning 80:69-74.

Hartman, H. 2002. Scaffolding and Cooperative Learning. Human Learning and Instruction, pp. 23-69. New York: City College of City University of New York.

Hatcher, R. 2006. A Guide to Academic Essay Writing in Cardiac Nursing. British Journal of Cardiac Nursing 1: 546-549.

Heijne-Penninga, M., J.B.M. Kuks, J. Schönrock-Adema, T.A.B. Snijders, T.A.B., and J. Cohen-Schotanus. 2008. Open-book Tests to Complement Assessment-programmes: Analysis of Open and Closed-book Tests. Advances in Health Sciences Education 13 (3): 263-273. 
Hill, B., and H. Green. 2012. Repeat Participation as a Function of Program Attractiveness, Socializing Opportunities, Loyalty and the Sportscape Across Three Sport Facility Contexts. Sport Management Review 15 (4): 485-499.

Hinkle, D.E., W. Wiersma, andS.G. Jurs. 1994. Applied Statistics for the Behavioural Sciences (3rd ed.). Boston: Houghton Miflin Company.

Holton, D., and D. Clarke. 2006. Scaffolding and Metacognition. International Journal of Mathematical Education in Science and Technology 17 (2):127-143.

Jones, H.M. 1997. An Introduction to Critical Thinking. Riverwood, NSW, Australia: Social Science Press.

Kaste, J. 2004. Scaffolding Through Cases: Diverse Constructivist Teaching in the Lliteracy Methods Course. Teaching and Teacher Education 20: 31-45.

Kennedy, M., M.B. Fisher, and R.H. Ennis. 1991. Critical Thinking: Literature Review and Needed Research. In L. Idol\&B.F. Jones (Eds.), Educational Values and Cognitive Instruction: Implications for Reform (pp. 11-40). Hillsdale, New Jersey: Lawrence Erlbaum \& Associates.

Knight, P.T. 2001. Complexity and Curriculum: A Process Approach to Curriculum-Making. Teaching in Higher Education 6 (3): 369-381.

Knowles, J., and S. McGloin. 2007. Developing Critical Analysis Skills in Academic Writing. Nursing Standard 21 (52): 35-37.

Kuhn, D. 1999. A Developmental Model of Critical Thinking. Educational Researcher 28 (2): 16-46.

Lewis, M. (2000) Teaching Collocation: Further Developments in the Lexical Approach. Hove: Language Teaching Publications. 
MacPherson, K. 1999. The development of Critical Thinking Skills in Undergraduate Supervisory Management Units: Efficacy of Student Peer Assessment. Assessment \& Evaluation in Higher Education 24 (3): 273-284.

MacCallum, R. C., K.F., Widaman, S. Zhang, and S. Hong 1999. Sample Size in Factor Analysis. Psychological Methods 4: 84-99.

Marginson, S., and M. Wende 2007. Globalisation and Higher Education. Organisation for Economic Co-operation and Development. Education Working Paper No. 8. Centre for Educational Research and Innovation (CERI), OECD Directorate for Education: 185.

Oliver, H., and R. Utermohlen.1995. An Innovative Teaching Strategy: Using Critical Thinking to Give Students a Guide to the Future (Eric Document Reproduction Services No. 389 702).

Ornstein A.C., and F.P. Hunkins. 1998. Curriculum: Foundations, Principles, and Issues. (4th ed.). Boston, MA: Allyn \& Bacon.

Roy, A., and B. Macchiette 2005. Debating the Issues: A tool for Augmenting Critical Thinking Skills of Marketing Students. Journal of Marketing Education 27 (3): 264276.

Sharma P. and M. Hannafin (2004). Scaffolding Critical Thinking in an Online Course: An Exploratory Study. Journal Educational Computing Research 31 (2): 181-208.

Shilbury, D., and P. Kellett. 2011. Sport Management in Australia. Sydney: Allen \& Unwin.

Sotiriadou, P. 2012. Sport Development Planning: The Sunny Golf Club. Sport Management Review 16: 514-523. doi: 10.1016/j.smr.2012.09.002 
Sotiriadou, P. 2011. Improving the Practicum Experience in Sport Management: A Case Study. European Sport Management Quarterly 11 (5): 525-546.

Suskie, L.A. 2004. Assessing Student Learning: A Common Sense Guide. Boston, Mass., Anker Publishing Company, Inc.

Thomas, T., T. Davis, and A. Kazlauskas. 2007. Embedding Critical Thinking in IS Curricula. Journal of Information Technology Education 6: 327-346.

Van Der Stuyf, R.R. 2002. Scaffolding as a Teaching Strategy. Adolescent Learning and Development, Section 0500A-Fall 2002, November 17: 2-13.

Vygotsk, L.S. 1963. Learning and Mental Development at School Age (J. Simon, Trans.). In B. Simon \& J. Simon (Eds.), Educational Psychology in the U.S.S.R. (pp. 21-34). London: Routledge and Kegan Paul.

Wade, C. 1995. Using Writing to Develop and Assess Critical Thinking. Teaching of Psychology 22 (1): 24-28.

Walton, M., and A. Archer. 2004. The Web and Information Literacy: Scaffolding the Use of Web Sources in a Project-based Curriculum. British Journal of Educational Technology 35 (2): 171-186.

Whitney, D.R., and L.S. Feldt. 1973. Analyzing Questionnaire Results: Multiple Tests of Hypotheses and Multivariate Hypotheses. Educational and Psychological Measurement 33: 365-380.

Woods, D. R., R.M Felder, A., Rugarcia, and J.E. Stice 2000. The Future of Engineering Education III. Developing Critical Skills. Change 4: 48-52. 
Woodward-Kron, R., and L. Remedios 2007. Classroom Discourse in Problem-Based Learning Classrooms in the Health Sciences. Australian Review of Applied Linguistics 30 (1): 9.1-9.18.

Wright, B.A., N. Duray, and T.L. Goodale. 1992. Assessing Perceptions of Recreation Center Service Quality: An Applicon of Recent Advancements in Service Quality Research. Journal of Park and Recreation Administration 10 (3): 33-47.

Young, T., and D. Bender-Slack. 2011. Scaffolding Pre-service Teachers’ Observations: Eye on the Future. Teaching Education 22 (3): 325-337.

Zakus, D.H., D.C. Malloy, and A. Edwards. 2007. Critical and Ethical Thinking in Sport Management: Philosophical Rationales and Examples of Methods. Sport Management Review 10 (2): 133-158.

Zeidler, D.L., N.G. Lederman, and S.C. Taylor. 1992. Fallacies and Student Discourse: Conceptualizing the Role of Critical Thinking in Science Education. Science Education 76 (4): 437-450. 